\title{
Syntactic reconstruction and reanalysis, semantic dead ends, and prefrontal cortex
}

\author{
Ken Ramshøj Christensen* \\ Institute for Language, Literature, and Culture, Aarhus University, Denmark \\ Center for Functionally Integrative Neuroscience, Aarhus University Hospital, Denmark
}

\section{A R T I C L E I N F O}

\section{Article history:}

Accepted 20 February 2010

Available online 16 March 2010

\section{Keywords:}

Interpretation

Parsing

Syntax

Structure

Garden path

Ellipsis

Language

Broca's area

Premotor cortex

Processing

\begin{abstract}
A B S T R A C T
The left inferior frontal gyrus (LIFG) is crucially has been found to be involved in syntactic processing of various kinds. This study investigates the cortical effects of two types of syntactic processes: (i) Reconstruction in ellipsis (recovery of left-out material given by context, More people have been to Paris than [...] to Oslo), using pseudo-elliptical structures ('dead ends') as control (More people have been to Paris than I have). (ii) Reanalysis in the face of structural ambiguity in syntactic 'garden paths', where the parser initially assigns an incorrect structure and is forced to reanalyze. Reanalysis and reconstruction require additional syntactic processing and were predicted to increase activation in areas otherwise involved in structural computation: LIFG (BA 44, 45), premotor BA 6, and posterior temporal BA 21, 22. This was borne out. The results showed an interaction effect of the types of construction in all three areas reflecting syntactic processing.
\end{abstract}

(c) 2010 Elsevier Inc. All rights reserved.

\section{Introduction}

The involvement of Broca's area (BA 44, 45) and of the left inferior frontal gyrus (LIFG) in general in syntactic processing is wellestablished. Various neuroimaging studies have found that (at least) three types of structural complexity engage the LIFG, namely: (i) structural ambiguity (including so-called garden path sentences, see below) (Fiebach, Vos, \& Friederici, 2004; Mason, Just, Keller, \& Carpenter, 2003; Stowe et al., 1998; Uchiyama et al., 2008); (ii) the complexity involved in clausal center-embedding versus right-branching structure (Just, Carpenter, Keller, Eddy, \& Thulborn, 1996; Stromswold, Caplan, Alpert, \& Rauch, 1996; Inui et al., 1998); and (iii) word order variation that establishes longdistance dependencies, an operation often referred to as 'syntactic movement' (Ben-Shachar, Hendler, Kahn, Ben-Bashat, \& Grodzinsky, 2003; Ben-Shachar, Palti, \& Grodzinsky, 2004; Bornkessel, Zysset, Friederici, von Cramon, \& Schlesewsky, 2005; BornkesselSchlesewsky, Schlesewsky, \& von Cramon, 2009; Christensen, 2008; Dogil et al., 2002; Fiebach, Schlesewsky, Lohmann, von Cramon, \& Friederici, 2005; Friederici, Fiebach, Schlesewsky, Bornkessel, \& von Cramon, 2006; Grewe et al., 2005; Just et al., 1996; Röder, Stock, Neville, Bien, \& Rösler, 2002).

In addition to the effect in LIFG, the posterior superior temporal gyrus (pSTG, BA 21, 22) has also been found to show increased acti-

\footnotetext{
* Address: Institute for Language, Literature, and Culture, Aarhus University, Jens Chr. Skous Vej 5, DK-8000 Aarhus C, Denmark. Fax: +45 89426540.

E-mail address: engkrc@hum.au.dk.
}

vation in conditions involving increased syntactic complexity of all three types, i.e., structural ambiguity (Bornkessel et al., 2005; Mason et al., 2003), center-embedding (Just et al., 1996; Stowe et al., 1998; Stromswold et al., 1996), and word order variation (Ben-Shachar et al., 2003, 2004; Bornkessel et al., 2005; Christensen, 2008; Dogil et al., 2002; Fiebach et al., 2005).

In fact, an increasing number of studies of sentence comprehension have also found activations in areas not normally associated with language (e.g., Stowe, Paans, Wijers, \& Zwarts, 2004; see Christensen, 2008, and Stowe, Haverkort, \& Zwarts, 2005, for overviews), in particular motor and premotor cortex (the precentral gyrus, PrCG, BA 4,6). For example, Hanakawa et al. (2002) found premotor cortex to be activated in non-motor tasks that involved rule-based, non-motor "mental-operation tasks", namely, numerical, verbal, and spatial tasks. Crucially, none of these tasks involved any motor activity, only cognitive, rule-based manipulation of representations in working memory.

The first aim of the present study was to investigate the cortical activation triggered by syntactic reconstruction in ellipsis, a syntactic operation that involves neither structural ambiguity nor a change in word order in the usual sense. Consider a clausal comparative construction (CCC), such as (1).

(1) More people have been to Paris than to Oslo.

Part of the meaning of (1) is that some people have been to Paris, and that the number of people who has been to Paris is larger than the number of people who has been to Oslo. A CCC such as (1) is syntactically complex in two ways (apart from the fact that one 
clause is embedded in the other); first, there is ellipsis, i.e., the process whereby one or more elements are elided (omitted or unpronounced) when they are supplied by the context (Johnson, 2001, 2005; Merchant, 2001; Park, 2001). The string [than to Oslo] is a prepositional phrase with an embedded clause in which [have been] has been elided. This is standardly represented as [than have been to Oslo], with the elided material in strike-through. Second, the than-phrase is interpreted as belonging to the quantifier phrase [More people], i.e., [More people than have been to Oslo] (compare More people than I can possibly count have been to Paris). That means that the embedded clause has been extraposed (shifted to the right). Thus, the comprehension of (1) requires recovery of what has been elided (i.e., undoing the ellipsis) and reconstruction of the extraposed embedded clause in its place of interpretation, see Fig. 1.

Pseudo-elliptical clausal comparatives, on the other hand, involve neither recovery of elided material nor reconstruction. Consider (2):

\section{(2) More people have been to Paris than I have.}

People tend at first glance to claim that an example like (2) is perfectly acceptable until they are asked to actually explain what it means; often, it is initially claimed to mean something like $I$ am not the only one who has been to Paris which, on reflection, is clearly not true. The problem is that, while (2) can easily be assigned a syntactic structure, it cannot be assigned a full semantic interpretation. Such sentences are henceforth referred to as (semantic) 'dead ends' (DE).

Like the CCC in (1), the DE in (2) involves clausal embedding. The two clauses, [More people have been to Paris] and [than I have], cannot be combined semantically, though both are well formed in other contexts. Thus, (2) is locally coherent, but globally incoherent. This apparently well-formed but nonsensical construction is famous in linguistics, though so far there are no published papers specific to the matter (but see Hinzen, 2006, p. 131; Montalbetti, 1984, p. 6; Myers, 2009; Smith, 2005, p. 10; Saddy \& Uriagereka, 2004). The effect is similar, but clearly not identical, to that of truly well-formed examples, such as, No head injury is too trivial to ignore, which by most speakers is assigned a wrong interpretation which they are very reluctant to give up (Natsopoulos, 1985; Wason \& Reich, 1979). Usually, people take it to mean No matter how trivial a head injury is, it should not be ignored, i.e., No head injury should be ignored. However, that is not what it means; it means No matter how trivial a head injury is, it should be ignored, i.e., All head injuries should be ignored. However, examples such as (2), are also initially assigned an apparent interpretation which people

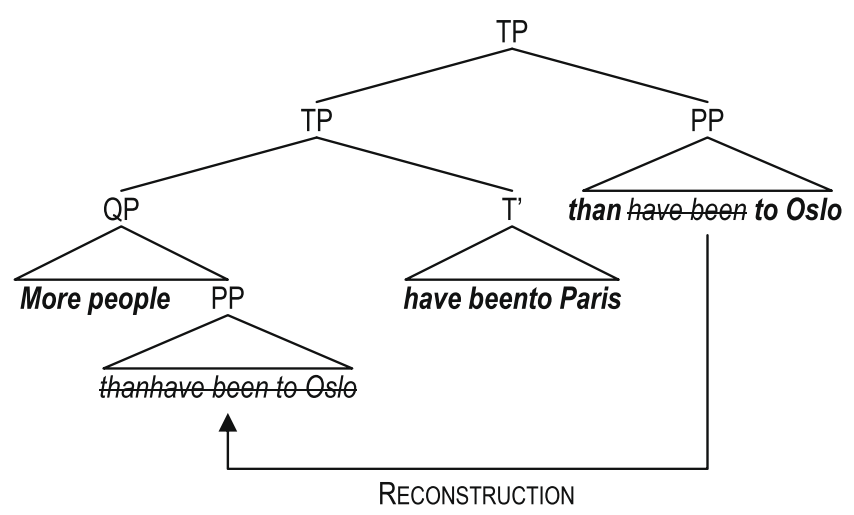

Fig. 1. Ellipsis and extraposition in a normal clausal comparative construction (CCC). Reconstruction involves uncovering the elided (strike-through) material and 'putting it back' from the place of articulation to its place of interpretation. $\mathrm{PP}=$ prepositional phrase, $\mathrm{QP}=$ quantifier phrase, $\mathrm{TP}=$ tense phrase. are very reluctant to give up, even though in reality the string has no real (globally congruous) interpretation, which is also why people have great difficulty explaining what they think it means. (Note in particular that, unlike in the CCC in (1), it does not follow from the DE in (2) that anyone has been to either Paris or Oslo.) This is thus an instance of 'shallow processing' (e.g., Ferreira \& Patson, 2007; Sanford \& Graesser, 2006; Sanford \& Sturt, 2002).

That the DE in (2) is meaningless (globally incongruous) becomes clear as soon as one tries to undo the apparent ellipsis. The only thing that the context supplies that also fits is [been to Paris], and the results is More people have been to Paris than I have been to Paris, which clearly does not make sense. Furthermore, trying reconstruction makes it crystal clear that it is meaningless: More people [than I have been to Paris] have been to Paris.

To our knowledge, neither CCCs nor DEs have yet been studied in cognitive neuroscience.

CCCs involve increased syntactic computation, and in the present study it was compared with another instance of increased syntactic computation, namely, syntactic 'garden paths' (GPs). The 'garden path' phenomenon refers to sentences with a local structural ambiguity that biases the language parser to assign the wrong structural interpretation (e.g., Ferreira, Christianson, \& Hollingworth, 2001; Frisch, Schlesewsky, Saddy, \& Alpermann, 2002; Mason et al., 2003; Osterhout, Holcomb, \& Swinney, 1994; Pritchett, 1992). At least in some instances, in the absence of additional cues, the parser relies on syntactic information and syntactic biases and may thus be 'led up the garden path'. The second aim of the study was to investigate whether GPs ensuing from a local structural ambiguity and reconstruction in CCCs give rise to similar cortical effects.

Basically, there are three conditions to be met for a sentence to be a GP: one, it must contain a local ambiguity; two, there is a preferred structural interpretation (parse) which is globally incorrect and which prompts reanalysis; and three, this reanalysis is often hard or even impossible. (There are many examples that meet the first two criteria, but crucially not the third, and since reanalysis is easy, they are not GPs, e.g., I know the man came back, where the man is locally ambiguous between object of know and subject of came back. For an overview, see Pritchett, 1992.) Probably the best-known and clearest examples of GPs are from English. Because English verbal inflection is very weak, local ambiguities arise in, for example, reduced relative clauses (The horse raced past the barn fell, where raced is initially interpreted as a finite main verb and the horse is interpreted as the subject; the correct interpretation has raced as a past participle, compare the horse that was raced past the barn fell) and with certain main verbs (The old man the boat, where man is ambiguous between noun and verb).

The language studied in the present experiment is Danish, and since Danish verbal inflection is not quite as weak as English inflection, similar examples cannot be constructed. Instead, the GP examples were based on a local ambiguity between an adjectivenoun and noun-noun sequence. Consider the examples in (3) and (4); the sentence in (3) is a GP, the one in (4) is a non-garden path (NGP). In (3), toughest is an adjective, and men is a noun, and together form the noun phrase (NP) complement of the determiner The. In turn this determiner phrase (DP) [DP The [NP toughest men]] is the subject of the sentence in (3).

(3) The toughest men know and use soap too.

(4) The toughest men know also use soap.

In (4), on the other hand, toughest and men do not form a constituent. Here, toughest is a noun, the head of the NP complement of The, and the noun men is the subject of the reduced relative clause modifying this NP: [DP The [NP toughest] [(that) men know]]. However, because the string the toughest men is structurally ambiguous, and because there is a strong preference for the DP 


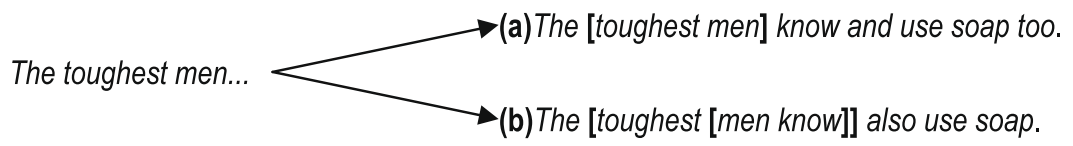

(a)

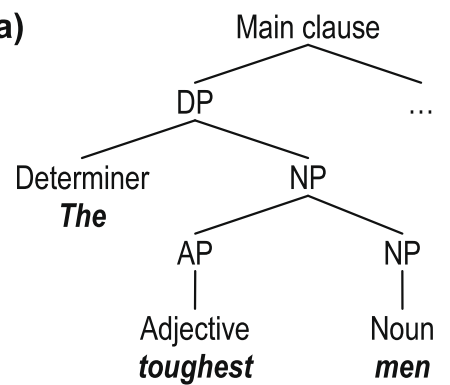

(b)

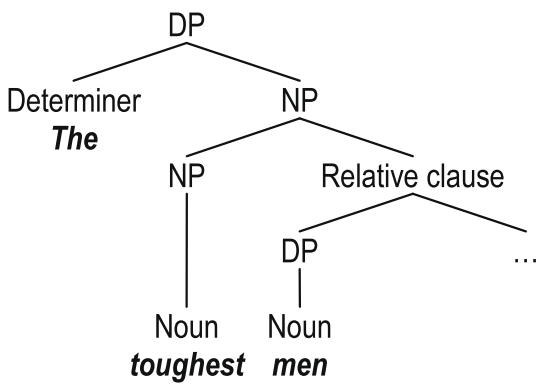

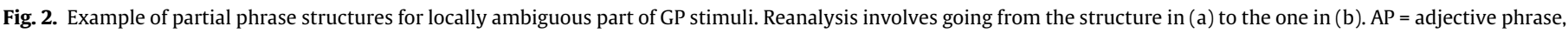
$\mathrm{DP}=$ determiner phrase, $\mathrm{NP}=$ noun phrase.

reading (as in (3)) over the relative clause reading, (4) is a GP, and as such it involves analysis. This reanalysis involves going from the structure in (a) to the one in (b) in Fig. 2.

The reason for using the term "DE" rather than "Semantic GP" is that DEs and GPs are similar but also different phenomena. GP refers to a situation where one reading of an ambiguity is chosen but subsequent information shows that it is wrong and conscious reanalysis is required. In DEs, a wrong reading is chosen. Here, however, the ambiguity is not local between two potential readings; instead the ambiguity is global between the correct nullreading and any wrong, non-null-reading. Again, conscious reflection is required but reanalysis is futile. (The use of DEs and similar nonsense in comedy, often with hidden camera, is well known. In Danish, there is even a special term for it, namely, sort snak, literally "black talk", meaning 'unintelligible/opaque speech'.)

Linguistically, GPs and DEs make an interesting pair because in a sense they are each other's mirror image. A GP is (temporarily) unacceptable, yet fully grammatical, and it is difficult to assign it a syntactic structure; a DE, on the other hand, is (temporarily) acceptable, yet ungrammatical, and it is impossible to assign it a semantic interpretation. In other words, a (syntactic) GP leads the parser astray, whereas a (semantic) DE does not go anywhere.

GPs and DEs can to a certain extent be seen as linguistic versions of ambiguous or impossible figures in the visual domain, i.e., optical illusions. The Necker cube, Fig. $3 \mathrm{~A}$ is an ambiguous wire-frame drawing of a cube in oblique perspective where the two squares can be either front or back. The object in Fig. 3B, sometimes called a blivet or a Devil's (tuning) fork, is an impossible (globally incongruous) object; in one end it has three round bars, in the other end two joined square bars. A Necker cube is structurally ambiguous and so is (a part of) a GP (though the ambiguity in

\section{(A)}

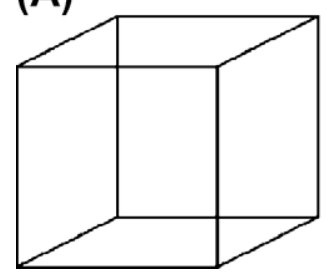

(B)

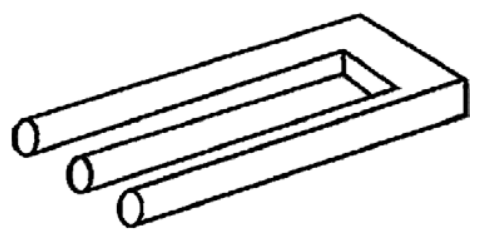

Fig. 3. Visual illusions. (A) A Necker cube where the two squares can be either front or back. This object structurally ambiguous. (B) Devil's tuning fork; an impossible object where the three round bars in one end cannot be reconciled with the two square ones in the other end. This object is locally well-formed (both ends are fine in isolation), but globally incongruous. the former is global and only local in the latter). A Devil's fork may at first glance appear to be a possible object (both ends are fine but irreconcilable), and the same goes for a DE.

Based on the syntactic analysis of GPs and CCCs and the neuroimaging literature on syntactic processing, the working hypothesis was that the two types of syntactic complexity, namely, reconstruction in CCC $(C C C>D E)$ and reanalysis in GPs $(G P>N G P)$ would induce similar, potentially overlapping, cortical activation patterns. Both are processes that involve projection of syntactic structure by 'recycling' elements in working memory (assigning a new structure in reanalysis of GPs, projection of recovered elided (understood) material in reconstruction in CCCs). Based on the neuroimaging literature on syntactic processing, the activation was predicted to be localized in three major regions of interest, namely, PrCG (BA 4,6), pSTG (BA 21,22), and LIFG. A number of researchers have argued for a functional subdivision of LIFG (e.g., Bookheimer, 2002; Dapretto \& Bookheimer, 1999; Fiebach et al., 2005; Friederici, 2002; Newman, Just, Keller, Roth, \& Carpenter, 2003), such that the posterior superior part, the pars opercularis (BA 44) is involved in syntactic processing, whereas the anterior inferior pars triangularis (BA 45) and pars orbitalis (BA 47) are involved in thematic integration and lexical semantic processing, respectively (but see Lindenberg, Fangerau, \& Seitz, 2007.) From this subdivision, we predicted reanalysis in GPs (GP > NGP) and reconstruction in CCCs to result in increased activation in pars opercularis (BA 44) due to the syntactic processing. The contrast between CCCs and DEs was also predicted to engage pars triangularis (BA 45) and/or pars orbitalis (BA 47) due to differences in semantic processing either reflecting increased cost of thematic integration of DEs (since they lack a coherent interpretation), i.e., an anomaly effect $(\mathrm{DE}>\mathrm{CCC})$, or reflecting a difference in processing of lexical material (CCC > DE).

Since both GPs and CCCs involve additional syntactic computation in the form of structural reconfiguration, it seems at least possible that involve the same cognitive processes and cortical activation patterns. Moreover, reanalysis in a GP is often difficult (sometimes even impossible) and requires conscious effort, whereas reconstruction is usually easy. It is thus possible that the activation that the two constructions induce reflects this difference such that GPs increase activation significantly more than CCCs. There were thus three hypotheses: (i) there is be an interaction between two factors, namely, GP vs. NGP and syntactic vs. semantic (where "semantic GPs" are DEs, and "semantic NGPs" are CCCs); (ii) the GP>NGP effect is bigger than CCC $>\mathrm{DE}$ : [(GP > NGP $)>(C C C>D E)]$; and (iii) this interaction effect is localized in PrCG (BA 4, 6), pSTG (BA 21, 22), and LIFG (primarily BA 44). 


\section{Materials and methods}

\subsection{Participants}

Nineteen native speakers of Danish (seven female, 12 male, 2237 years of age, average 27.5 years) volunteered to participate in the study. They were all right-handed and had no medical history of mental deficits or neurological trauma. All had normal or corrected-to-normal vision. Informed written consent was obtained prior to the experiment. The experiment was approved by the Research Ethical Committee for Aarhus County, Denmark.

\subsection{Materials}

The experimental task was a probe-to-target matching task (or probe-verification task) (see Fig. 4). A biclausal affirmative or negative target sentences (either a GP with an embedded relative clause, a NGP with two coordinated clauses, a pseudo-elliptic DE, or a truly elliptic CCC, see Table 1) was presented visually as a whole for $5 \mathrm{~s}$, followed by an arrow projected in the center of the screen, which the participants were instructed to interpret as something like "from this it follows that", and which remained onscreen for $1 \mathrm{~s}$. Then an affirmative or negative monoclausal probe was presented for $3 \mathrm{~s}$. The task was to answer yes or no, within the $3 \mathrm{~s}$ the probe was on the screen, by pressing a left or right button with the right index or middle finger, respectively. Subsequently, a plus was shown centered in the screen for $2 \mathrm{~s}$, before the next target appeared.

Before scanning, the participants were trained on the task with a small set of stimuli to make sure they understood the task. The training set consisted of 16 tokens, four from each condition (two negative and two affirmative): two negative CCCs, two affirmative CCCs, two negative DEs, two affirmative DEs, etc. A $6 \mathrm{~s}$ 'pause' condition occurred after every eight events. The sentences in the training set did not occur in the actual experiment. The training sessions took place outside the scanner room and took 3:08 min each.
The entire stimulus set consisted of a total of 112 events (target-probe pairs): 28 CCCs, 28 DEs, 28 GPs, and 28 NGPs. Each target example appeared once as an affirmative sentence and once as a negative sentence. The GPs/NGPs appeared once with the adverb også 'also' (affirmative) and once with the adverb ikke 'not' (negative); likewise, each of the DEs and CCCs appeared once with flere 'more' (affirmative) and once with færre 'fewer' (negative). Representative examples of stimulus targets and probes are given in Table 1 (see also the examples in (1) and (2) above).

There was no baseline as such, even though there was a $6 \mathrm{~s}$ pause with a " $*$ " centered on the screen after every eight events (i.e., after eight target-probe pairs) to reduce mental fatigue. The pause was modeled in the first-level analysis for each subject but was not used in the second-level analyzes.

The order of presentation of the four types was randomized, and they occurred with the following mean intervals effectively jittering the onset of events: CCCs: $44.7 \mathrm{~s}$. (range: 11-107, std. dev. $=34.4$ ), DEs: 48.7 s. (range: $11-148$, std. dev. $=38.2$ ), GPs: 47.9 s. (range: $11-129$, std. dev. $=28.8$ ), NGPs: 47.0 s. (range: $11-$ 203, std. dev. $=47.5$ ). Admittedly, it is a weakness that the interval (the "+" in Fig. 4) between a probe and the following unrelated target is constant (namely, $2 \mathrm{~s}$ ). However, since the order of conditions was randomized, and since all targets are potentially affected by an additive 'spill over' from a preceding unrelated probe, the average effect should be leveled out under subtraction.

The software for stimulus presentation and recording of behavioral data was tailor-made for the experiment.

\subsection{Procedure}

Functional MR images were acquired on a General Electrics 3 Tesla system using a standard head coil. The experiment consisted of a single scanning session per participant. Scans were performed using an echo planar imaging sequence with a flip angle $=90$, $\mathrm{TE}=30$, and $\mathrm{TR}=3 \mathrm{~s}$; scanning sequence consisted of a T1weighted localizer and $T 2 *$-weighted functional images. Each volume consisted of 39 axial slices covering the entire cerebrum and cerebellum (slice thickness $=3.5 \mathrm{~mm}$, spacing $=0$ ).

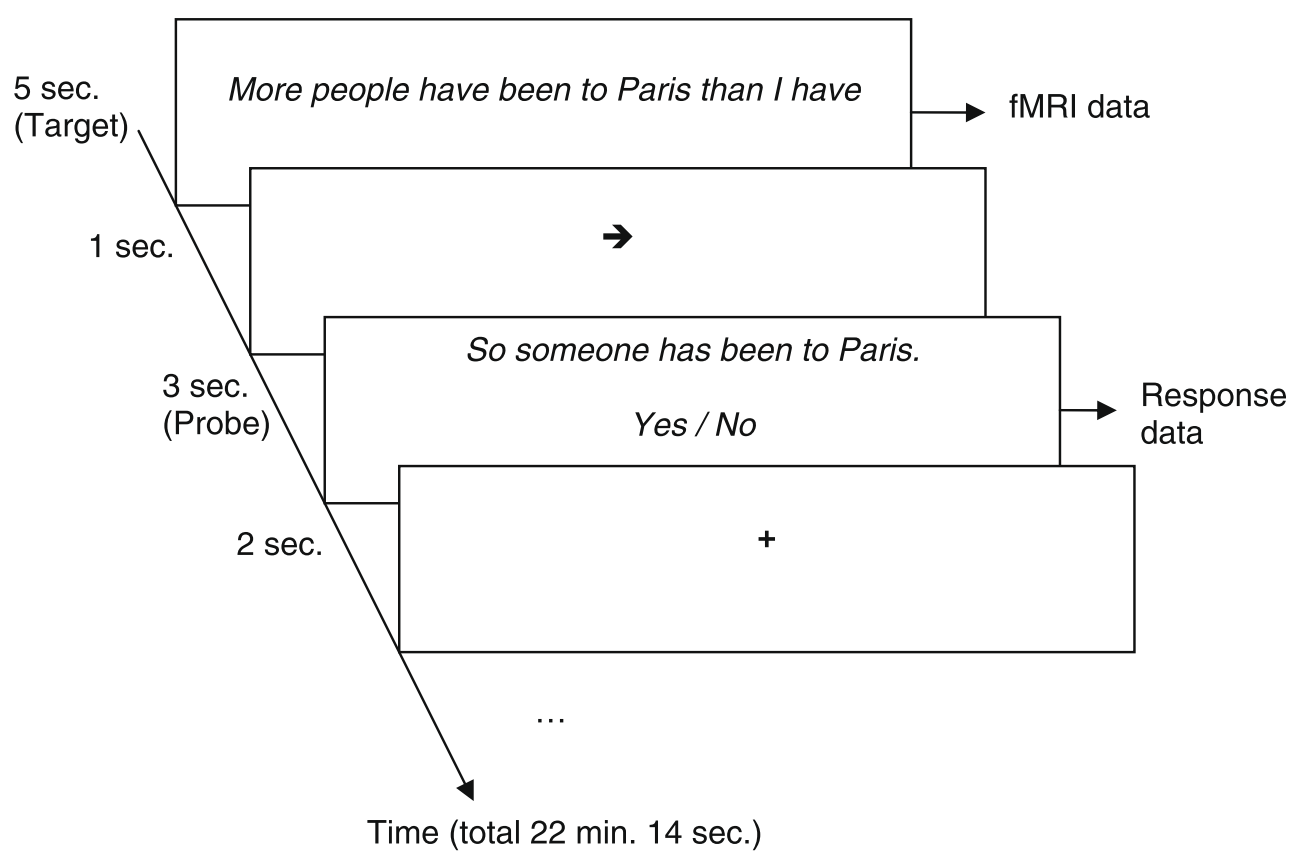

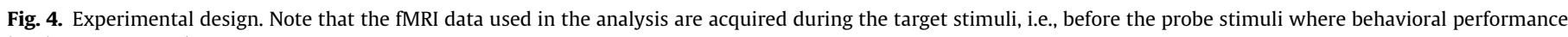
levels are measured. 
Table 1

Stimulus material.

\begin{tabular}{|c|c|}
\hline Target & Probe \\
\hline \multicolumn{2}{|l|}{$\mathrm{CCC}$} \\
\hline Flere mænd har boet i telt end på hotel. & Nogen har altså boet i telt. \\
\hline More men have lived in tent than on hotel. & Someone has then lived in tent. \\
\hline "More men have lived in a tent than in a hotel." & "So, someone has lived in a tent." \\
\hline Flere børn har kigget på dyr end på biler. & Nogen har altså kigget på dyr. \\
\hline More children have looked at animals than at cars. & Someone has then looked at animals. \\
\hline "More children have looked at animals than at cars." & "So, someone has been looking at animals." \\
\hline \multicolumn{2}{|l|}{$D E$} \\
\hline Flere mænd har boet i telt end Marie har. & Nogen har altså boet i telt. \\
\hline More men have lived in tent than Mary has. & Someone has then lived in tent. \\
\hline "More men have lived in a tent than Mary has." & "So, someone has lived in a tent." \\
\hline Flere børn har kigget på dyr end du har. & Nogen har altså kigget på dyr. \\
\hline More children have looked at animals than you have. & Someone has then looked at animals. \\
\hline "More children have looked at animals than you have." & "So, someone has been looking at animals." \\
\hline \multicolumn{2}{|l|}{$G P$} \\
\hline De mærkeligste mænd kender bruger også sminke. & Visse mærkelige personer bruger også sminke. \\
\hline The strangest men know use also make-up. & Certain strange persons use also make-up. \\
\hline "The strangest men know use make-up, too." & "Certain strange persons use make-up, too." \\
\hline De flotteste kvinder kender spiser også kager. & Visse flotte personer spiser også kager \\
\hline The prettiest women know eat also cakes. & Certain pretty persons eat also cake. \\
\hline "The prettiest women know eat cake, too." & "Certain pretty persons eat cake, too." \\
\hline \multicolumn{2}{|l|}{ NGP } \\
\hline De mærkeligste mænd kender og bruger også sminke. & Visse mærkelige personer bruger også sminke. \\
\hline The strangest men know and use also make-up. & Certain strange persons use also make-up. \\
\hline "The strangest men know and use make-up, too." & "Certain strange persons use make-up, too." \\
\hline De flotteste kvinder kender og spiser også kager. & Visse flotte personer spiser også kager \\
\hline The prettiest women know and eat also cakes. & Certain pretty persons eat also cake. \\
\hline "The prettiest women know and eat cake, too." & "Certain pretty persons eat cake, too." \\
\hline
\end{tabular}

FOV $=240 \times 240 \mathrm{~mm}$, matrix $=128 \times 128$ voxels (in-plane resolution $=1.875 \times 1.875 \mathrm{~mm}$ ), acquisition bandwidth $=3.906 \mathrm{kHz}$. Total fMRI scan time $=22: 14 \mathrm{~min}$ resulting in 445 full brain volumes per subject. In addition, at the beginning of each fMRI session, five dummy acquisitions were made allowing the magnetic field to align.

\subsection{Data analysis}

The data was analyzed with SPM8 (Wellcome Department of Imaging Neuroscience, University College London). The imaging data were realigned, normalized (reslicing the voxels to $2 \times 2 \times 2 \mathrm{~mm}$ ), and smoothed (10 mm FWHM). All events were modeled using the standard hemodynamic response function of SPM8 and estimated for each participant, using a general linear model with a 128-s high-pass filter, and AR(1) modeling of serial correlation, before being submitted to a second-level, random-effect analysis.

Only the target conditions were modeled, not the probe conditions; i.e., the fMRI analysis was applied to images acquired during the targets, not the probes where the behavioral data was recorded, thus avoiding motor artifacts in the imaging data (see Fig. 4). (The analysis of negative vs. affirmative is analyzed elsewhere, see Christensen, 2009, and will not be discussed here. Suffice it to say that negative sentences increased activation in left premotor cortex (BA 6) relative to affirmative sentences.)

In the first-level (single-subject) analysis, the four task-related regressors, i.e., GP, NGP, CCC, and DE, as well as the 'pauses' were modeled, with the onset of each target event as onset of the hemodynamic response function. The temporal derivatives of each of these five regressors were also modeled to correct for differences in peak latency. The first-level beta estimates of the four task conditions were entered into a second-level full factorial ANOVA. In addition, to correct for subject-specific variation in offset, a regressor for each subject was included modeling the average BOLD response across the four task conditions.

\section{Results}

\subsection{Behavioral results}

The behavioral data was measured in the offline probe condition. The response time was measured from the moment the probe text was projected in the screen. Time-out for response was $3000 \mathrm{~ms}$ (cf. Fig. 4). The events where a participant failed to respond within the time window were discarded from the analysis of response time as well as performance (\% correct).

One-way repeated measures ANOVAs revealed no significant difference in response time between CCC and DE or between GP and NGP ( $p=1.000$, Bonferroni-corrected; $F=3.181$; CCC: average across participants and sentence tokens $=1642.3 \mathrm{~ms}, \mathrm{SD}=302.2$; $\mathrm{DE}$ : $1616.5 \mathrm{~ms}, \mathrm{SD}=403.9$; $\mathrm{GP}: 1827.4 \mathrm{~ms}, \quad \mathrm{SD}=307.1$; NGP: $1893.2 \mathrm{~ms}, \mathrm{SD}=268.9$ ). In the performance levels (\% correct), there was a significant difference between GP and NGP $(p=.013$, Bonferroni-corrected; GP: $66.2 \%$ correct, $\mathrm{SD}=16.9$; NGP: $81.9 \%, \mathrm{SD}=12.5$ ) but not between CCC and DE ( $p=.864$, Bonferroni-corrected; CCC: 75.4\%, SD = 17.6; DE: 61.4\%, SD = 25.5) $(F=3.101)$.

It is important to stress that the behavioral data measured offline responses, and hence does not directly reflect online language processing, and it does not directly correlate with contrasts in BOLD response in the neuroimaging data. For this reason no strong conclusion can be drawn from differences in behavioral response.

\subsection{Imaging results}

To control for false positives, the imaging results were thresholded such that only clusters containing at least 50 contiguous voxels $\left(400 \mathrm{~mm}^{3}\right)$ were included. The threshold of significance at the voxel level was set to $p<.05$, FWE corrected for multiple comparisons. All brain coordinates reported in this paper are MNI coordinates.

Table 2 shows the results of the positive interaction between the two task contrasts, i.e., $(\mathrm{GP}>\mathrm{NGP})>(\mathrm{CCC}>\mathrm{DE})$. Clusters have local maxima in the precuneus (BA 7) bilaterally, premotor cortex 
Table 2

The activation clusters of the interaction-effects, $(\mathrm{GP}>\mathrm{NGP})>(\mathrm{CCC}>\mathrm{DE}) ; 1$ voxel $=8 \mathrm{~mm}^{3}$; $p$-values corrected for multiple comparisons. Coordinates refer to the MNI space.

\begin{tabular}{|c|c|c|c|c|c|c|}
\hline Cluster size (voxels) & $p$-Value (FWE) & $T$-Value & MNI $x$ & MNI $y$ & MNI $z$ & Location of local maxima \\
\hline \multirow[t]{3}{*}{1648} & 0.000 & 7.63 & 24 & -80 & 52 & BA 7, precuneus \\
\hline & 0.001 & 6.23 & 30 & -60 & 48 & BA 7, superior parietal lobule \\
\hline & 0.007 & 5.55 & 26 & -68 & 28 & BA 7 , precuneus \\
\hline \multirow[t]{3}{*}{2007} & 0.000 & 7.53 & -30 & -2 & 38 & BA 6, precentral gyrus \\
\hline & 0.000 & 7.44 & -46 & -14 & 50 & BA 4, precentral gyrus \\
\hline & 0.000 & 7.41 & -42 & -2 & 36 & BA 6, precentral gyrus \\
\hline \multirow[t]{3}{*}{621} & 0.000 & 6.95 & -58 & -48 & 8 & BA 21 , middle temporal gyrus \\
\hline & 0.001 & 6.16 & -48 & -52 & -8 & BA 37, sub-lobal \\
\hline & 0.005 & 5.69 & -46 & -48 & 2 & BA 22 , middle temporal gyrus \\
\hline \multirow[t]{3}{*}{671} & 0.001 & 6.39 & -24 & -62 & 40 & BA 7, superior parietal lobule \\
\hline & 0.001 & 6.22 & -24 & -70 & 44 & BA 7, superior parietal lobule \\
\hline & 0.006 & 5.63 & -26 & -76 & 32 & BA 19, precuneus \\
\hline \multirow[t]{2}{*}{304} & 0.001 & 6.26 & 40 & 16 & 36 & BA 9, middle frontal gyrus \\
\hline & 0.011 & 5.44 & 44 & 4 & 42 & BA 9, inferior frontal gyrus \\
\hline 227 & 0.002 & 6.04 & 32 & -26 & 66 & BA 4, precentral gyrus \\
\hline 109 & 0.003 & 5.85 & -4 & -4 & 70 & BA 6 , superior frontal gyrus \\
\hline
\end{tabular}

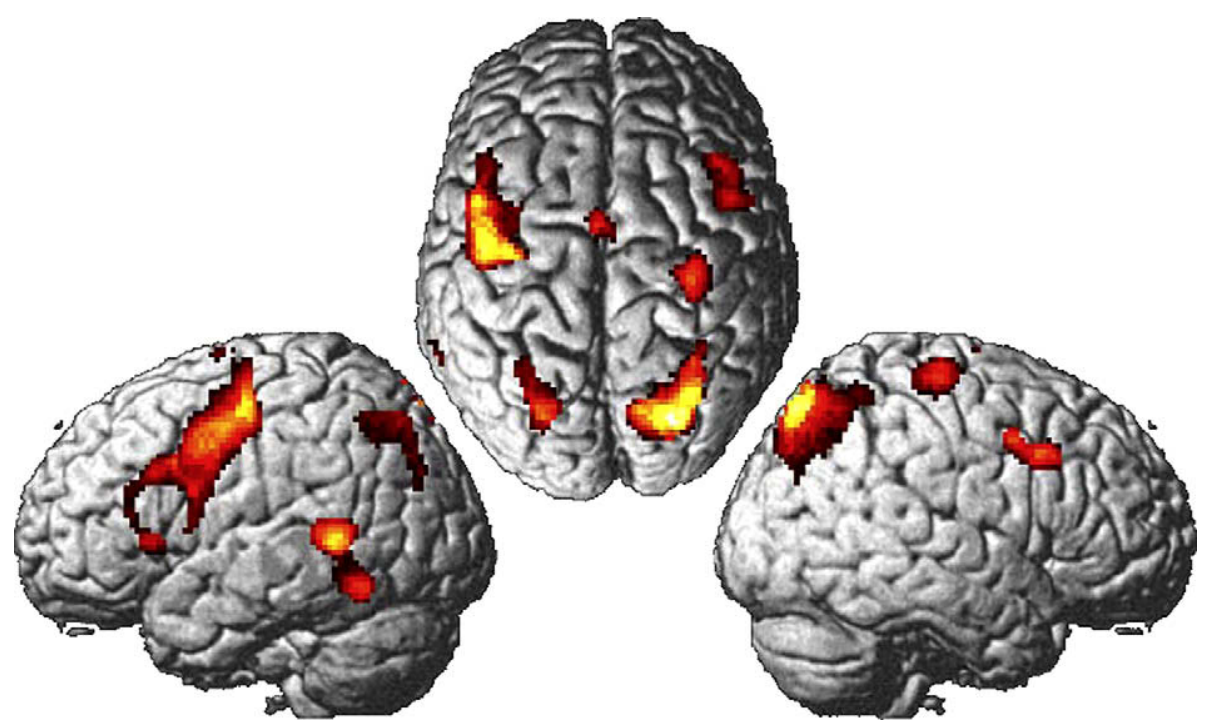

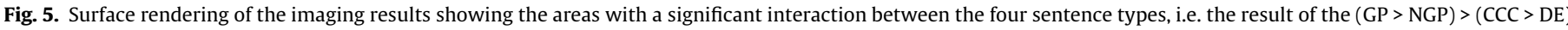
contrast.

(BA 4, 6) bilaterally, left BA 9 and left posterior temporal cortex (BA 21, 22, 37), see also Figs. 3 and 4.

To test if the large activation cluster in the left PrCG extended into the LIFG, subsequent small-volume correction (SVC) was applied with masks of BA 44, 45 and 47, defined using the WFU (Wake Forest University School of Medicine) Pickatlas (Maldjian, Laurienti, Kraft, \& Burdette, 2003, 2004) referencing in the Talairach atlas. The SVC revealed 23 voxels in BA $44[-52,4,16]$ and
22 voxels in BA $45[-42,20,6]$, see Fig. 6 , in the posterior and anterior tip of the big L-PrCG cluster in Fig. 5, respectively. No activation was found in BA 47. SVC also showed the activation cluster to extend into left BA 9 (260 voxels).

Fig. 7 shows the interaction patterns from left BA 4,6, left posterior middle/superior temporal gyrus (BA 21, 22) right BA 9, right BA 4, dorsal/medial BA 6 (supplementary motor area, SMA), and LIFG. The overall pattern is that the GP > NGP difference is signifi-

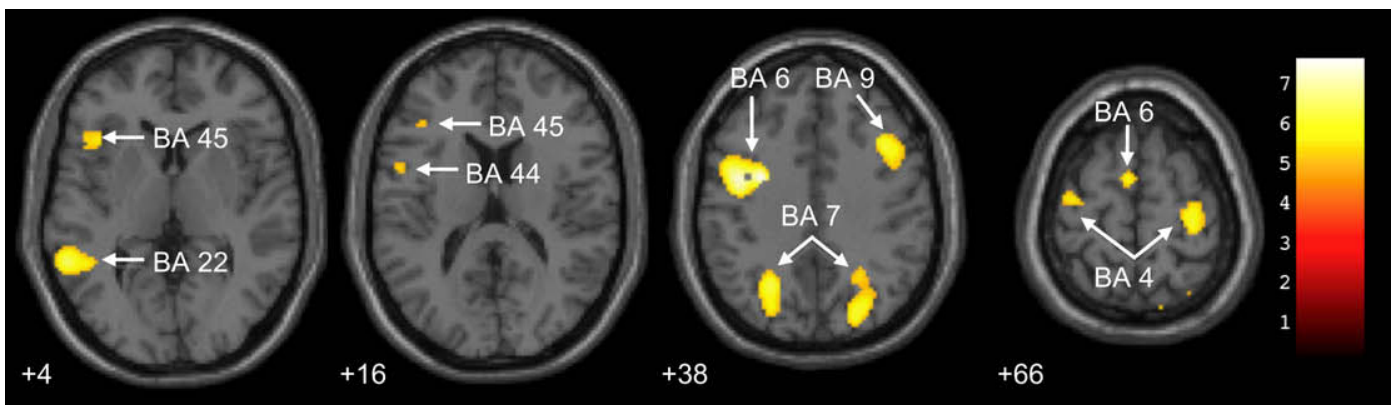

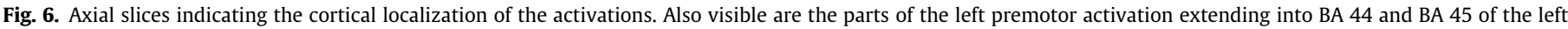
inferior frontal gyrus. 

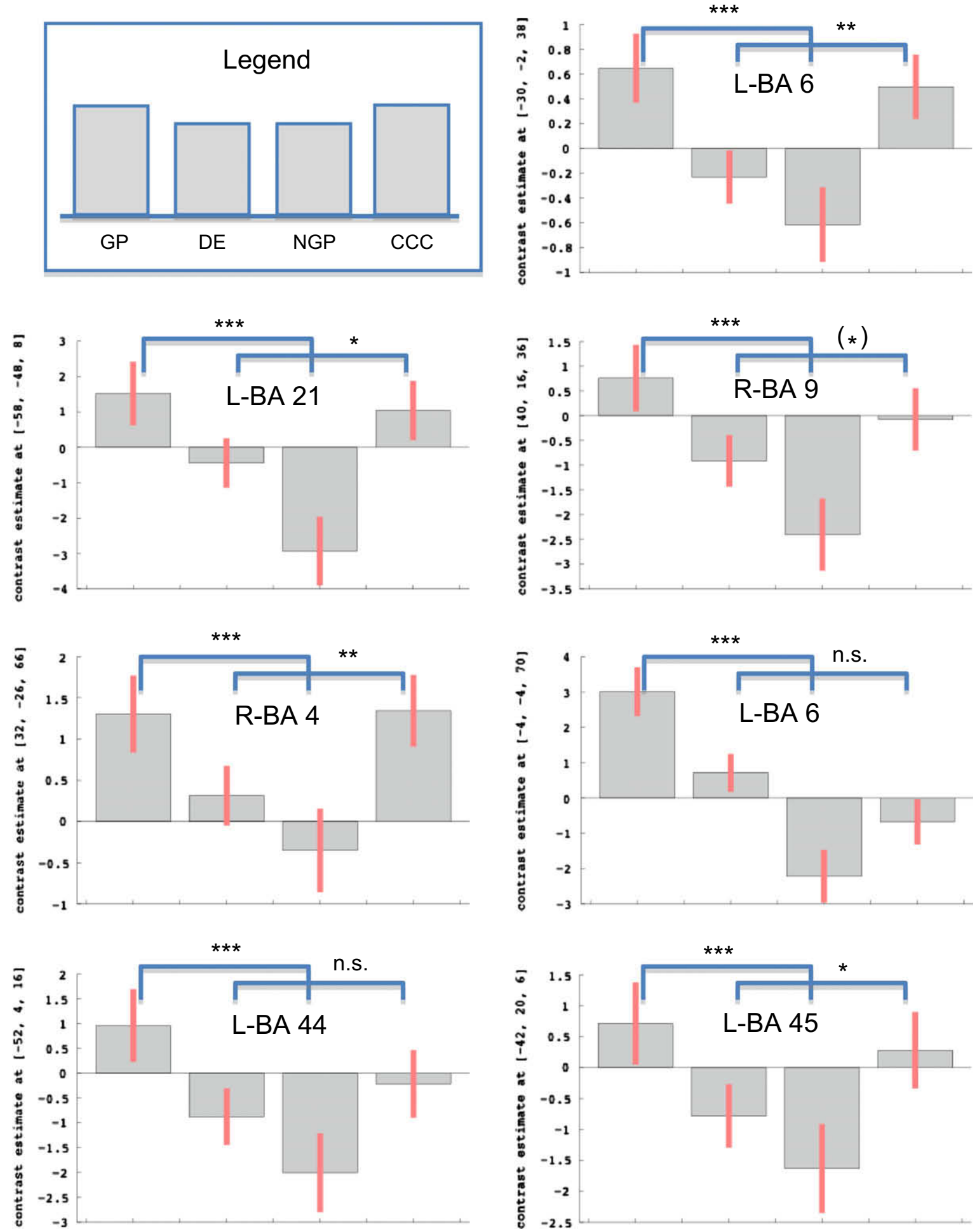

Fig. 7. Differences in activation levels in the local maxima of the activation clusters.

cantly bigger than CCC $>$ DE $(p<.05$, FWE). Furthermore, GPs increase activation, while NGPs decrease activation, leading to a big significant differences ( $p<.05$, FWE). Similarly CCCs tend to increase activation, and DEs to decrease it, though the differences between the two are significant with uncorrected p-values only, cf. Fig. 7. (The same pattern is found in the occipito-parietal clusters with local maxima in BA 7: GPs increase and NGPs decrease activation, and the difference is significant, bilaterally $[p<.05$, FWE]; the difference between CCCs and DEs is significant in the right hemi- sphere $[p<.05$, uncorrected $]$ with a slight increase and decrease in activation for CCCs and DEs, respectively; in the left hemisphere, both CCCs and DEs decrease activation and the difference is not significant.)

\section{Discussion}

The behavioral results showed no significant difference in response time between the probes (CCC vs. DE and GP vs. NGP). 
There was no significant difference in performance level between probes following CCCs and probes following DEs. The only significant difference in the behavioral data was in the levels of correct performance; participants performed better on probes following NGPs than on probes following GPs. Keeping in mind that the behavioral data was recorded offline, no conclusions regarding the processing of the target sentences can be drawn from it. However, the fact that performance was better on probes following NGPs than probes following GPs could be due to lingering (partial) erroneous representations, i.e., the erroneous interpretation induced by the syntactic GP-effect, the local structural ambiguity. Reanalysis is not always successful and sometimes the initial partial and erroneous parse lingers and influence interpretation (Ferreira \& Patson, 2007; Ferreira et al., 2001; Fodor \& Inoue, 1998). For example, in (4), the initial and wrong interpretation is that [The toughest men] is the subject of [know]; subsequently [men] is reanalyzed as the subject of [know] whereas [the toughest] is the subject of [use]. After reanalysis, however, the initial partial representation may linger such that people recall [the toughest men] as a constituent and as the subject of [know]. The lack of significant behavioral difference between CCCs and DEs could be due to weak or absent 'lingering effects' (since people have difficulty explaining what they think DEs mean), or, more likely, given the rather poor performance on both (CCCs: $75.4 \%$, DEs: $61.4 \%$ ), that the performance on CCCs was not good enough. It may also reflect the difficulty of the task of representing and processing scalar quantification and comparison (cf., Aoun \& Li, 1989; Geurts \& van der Slik, 2005; Kurtzman \& MacDonald, 1993).

In the imaging data, NGPs showed decreased activation (Fig. 7), and that may be taken to reflect that NGPs are relatively easy to parse. Since the same is the case for DEs in LIFG, left premotor (BA 4, 6), and left posterior temporal cortex (BA 21, 22), it may also be taken to suggest that DEs are easy to process, even though they are nonsensical, again suggesting 'shallow processing'. Importantly, decreased activation does not correlate with 'normal' sentences (i.e., NGP and CCC). Through NGPs induce decreased activation, the 'normal' CCCs do not; the nonsensical DEs, on the other hand, decrease activation.

As argued in the introduction, DEs are meaningless (globally incongruous). However, someone might argue that DEs are semantically anomalous, though in a much more subtle way than the more typical semantic and pragmatic anomalies (e.g., selectional restriction violations such as He spread the warm bread with butter/*socks) which have also been found to activate LIFG (Cardillo, Aydelott, Matthews, \& Devlin, 2004; Hagoort, Hald, Bastiaansen, \& Petersson, 2004; Kiehl, Liddle, \& Hopfinger, 2002; Kuperberg et al., 2003). If it were the case that DEs were anomalous rather than meaningless, we would expect that they would be processed similarly to other types of semantic/pragmatic anomalies and hence that the DE > CCC contrast would show increased activation in LIFG. However, with the activation levels going down for normal NGPs as well as DEs and up for GPs and normal CCCs, a semantic account is difficult to maintain. The oddballs (GPs and DEs) do not show similar activation, and in particular the DEs decrease activation - the inverse of the pattern normally found with semantic oddballs. This suggests that the apparently well-formed but semantically vacuous DEs, are different in nature or at least are processed differently from the usual semantic or pragmatic anomalies in the literature. (Admittedly, this final point is weakened by the fact that the study did not include any of these anomalies.) Furthermore, it is usually assumed that the increase in activation in LIFG with anomalies/oddballs reflects relative difficulty of semantico-pragmatic "integration". As shown in Fig. 7, NGPs have the strongest deactivations, and hence are easiest to integrate; GPs have the highest activation and are most difficult to integrate, and CCCs fall in between GPs and NGPs. If the 'integration' ap- proach is correct, then it seems that DEs are also easy to integrate semantically, given that they show significantly less activation than CCCs. Again, this suggests shallow processing.

GPs and CCCs induced similar increases in cortical activation relative to controls. From a syntactic point of view, this was to be expected since both GPs and CCCs involve increased syntactic computation, namely, reanalysis and reconstruction, respectively. Both showed increased activation in the LIFG and in premotor cortex (PrCG: BA 4, 6, 9), bilaterally (Figs. 4 and 5). There were neither motor responses nor sensory stimuli in the target conditions (only the target conditions were modeled, not the probe conditions), so the activation is not due to actual motor activity (furthermore, the fact that the participants responded with the right index or middle finger cannot account for the bilateral effect). The fact that both GP > NGP and CCC > DE activate in particular LIFG, left posterior middle and superior temporal cortex (BA 21,22), and left premotor cortex (BA 4,6,9) also suggests that the effect is related to syntactic computation, not to semantic differences in the contrasts. As mentioned in the introduction, it has been argued that LIFG should be divided into functional subcomponents with BA 44 involved primarily in syntactic computation, BA 45 in semantic/thematic integration, and BA 47 in lexical retrieval (e.g., Bookheimer, 2002). No effect was found in BA 47; furthermore, the pattern in BA 45 is the same as in BA 44 (though CCC $>$ DE is only significant in BA 45), as well as in the other clusters in general.

It has, however, been argued that the LIFG has a very general cognitive function, namely, in detection and resolution of incompatible stimulus representations; more specifically, the role of LIFG in sentence comprehension is to implement reanalysis in the face of misinterpretation, as for example in GPs (see Novick, Trueswell, \& Thompson-Schill, 2005, for a review). The effect of GP > NGP in the present study is fully compatible with this idea. However, why the $\mathrm{CCC}>\mathrm{DE}$ contrast was also significant in part of LIFG (BA 45) is not clear since there is no representational ambiguity involved, no conflict, no misinterpretation, and no need to suppress a preferred but incorrect representation in favor of a dispreferred but correct one. Both the CCC in (1) and the DE in (2) involve late attachment of the than-phrase to the top-most node in the syntactic structure. In particular, the CCC in (1) is not structurally ambiguous. The than-phrase cannot be interpreted as modifying and being attached to Paris, not even temporarily; it is unambiguously part of the more people constituent. The whole trick of the DE in (2) is that the structure is apparently the same. The than-phrase cannot be interpreted being attached to Paris, but it cannot be part of the more people constituent either; there is pseudo-ellipsis and no reconstruction.

The LIFG activation is compatible with the idea that it is triggered by structural complexity in the difference in sentence embedding. It has been shown that contrasting center-embedded sentences with right-embedded sentences increases activation in LIFG (Just et al., 1996; Stromswold, 1996; Inui et al., 1998). The present GP > NGP contrast is similar since the GPs have centerembedding even though the NGPs have coordination rather than right-embedding. In the CCC condition, the reconstruction site is also center-embedded. (See also Hagoort, 2005, approach in which Broca's area is hypothesized to play a role in 'unification' of (partial) representations.) The activation in the LIFG triggered by GPs and CCCs is also compatible with the 'interface' approach in Christensen (2008) according to which the LIFG is involved in the interfacing between the computational system of syntax and other cognitive systems, including information structure. In particular, it is argued that there is a correlation between LIFG activation and syntactic operations involving the top-most node of the clause, the so-called complementiser phrase (CP). The $\mathrm{CP}$ is crucially involved in, for example, questions and sentential embedding such as relative clauses. Parsing a CCC, and not a DE, involves recon- 
struction of a $\mathrm{CP}$, embedded under the preposition than, in the middle of the clause. The activation found in LIFG, then, may reflect interfacing between linguistic systems mapping form to function (crucially involving the CP-layer of the syntactic structure), whereas the activation in PrCG (BA 4,6,9) reflects purely structural differences in the syntactic structure.

The bulk of the frontal activation, however, is not located in LIFG. Instead, it is a left-lateralized effect in premotor cortex (PrCG: BA 4, 6, 9). The fact that motor and premotor cortex in the PrCG is engaged is compatible with the fact that skeletal motor movement also require rule-governed programming in the sequencing of hierarchical representations (Fuster, 2003; Grézes \& Decety, 2001; Schubotz \& von Cramon, 2002, 2003). (Corballis, 1989, has even suggested an evolutionary link between the two, but see Bickerton, 2007, and Grézes \& Decety, 2001.) It is also compatible with this region being involved in rule-based, mental-operation tasks and syntactic computation (Ben-Shachar et al., 2003, 2004; Christensen, 2008, 2009; Dogil et al., 2002; Hanakawa et al., 2002; Röder et al., 2002). Working memory demands, in particular with stimuli that can be recoded as structured chunks, have been shown to correlate with activation in the inferior parietal cortex and dorsolateral prefrontal cortex, as well as in the premotor cortex (Bor, Cumming, Scott, \& Owen, 2004; Bor \& Owen, 2007; Smith \& Jonides, 1999). As argued above, the trigger for activation is syntactic. GPs and CCCs involve restructuring of syntactic representations in working memory, a change in relation between linear order and hierarchical structure. That is not to say that reanalysis in GPs and reconstruction in CCCs are reducible to one and the same phenomenon. Compared to controls, they both involve additional syntactic processing, in particular the syntactic structure-building process called Merge, which essentially is the recursive process by which two constituents (morphemes, words, phrases, sentences) combine to form larger constituents. Given that both also involve a 'reparse' (either a reanalysis or a construction), they also require additional working memory top hold the representations under analysis. Reanalysis and reconstruction thus employ the same subcomponents of the grammatical parsing system and working memory systems. However, GPs and CCCs are fundamentally different. GPs require reanalysis making processing more difficult, which as such may hinder communication, or at least make it less efficient from the perspective if the receiver (listener/reader). Ellipsis, on the hand, is a way of reducing the load on phonological working memory; without ellipsis, sentences may get much 'heavier' or longer and hence require more working memory, for example Susan read that crazy book about the pyramids twice last year, and John did [read that crazy book about the pyramids twice last year] too (Johnson, 2001, 2005; Merchant, 2001; Shapiro, Hestvik, Lesan, \& Garcia, 2003).

\section{Conclusions}

The present experiment investigated the neural response to syntactic reanalysis in syntactic garden path sentences (GPs) and reconstruction in elliptical clausal comparative constructions (CCCs) relative to controls, namely, non-garden paths (NGPs) and apparently well-formed but globally incongruous semantic dead ends (DEs), respectively. The predictions were that (i) that there was an interaction between two factors, namely, GP vs. NGP and syntactic vs. semantic (where "semantic GPs" are DEs, and "semantic NGPs" are CCCs); (ii) that the GP > NGP effect was bigger than $\mathrm{CCC}>\mathrm{DE}$ : $[(\mathrm{GP}>\mathrm{NGP})>(\mathrm{CCC}>\mathrm{DE})]$; and (iii) that this interaction effect was localized in premotor cortex (PrCG: BA 4,6), posterior temporal cortex (BA 21,22), and LIFG (primarily BA 44). These hypotheses were borne out. It was argued that the trigger for the resulting activation patterns was syntactic, namely, the increased syntactic computation involved in reanalysis and reconstruction. Within the LIFG, the contrast between CCCs and DEs was also predicted to engage pars triangularis (BA 45) and/or pars orbitalis (BA 47 ) due to differences in semantic processing either reflecting increased cost of thematic integration of DEs (since they lack a coherent interpretation), i.e., an anomaly effect ( $D E>C C C$ ), or reflecting a difference in processing of lexical material $(C C C>D E)$. The results revealed no effect in BA 47; furthermore, the activation found in BA 45 was not an anomaly effect since it was triggered by the $\mathrm{CCC}>\mathrm{DE}$ contrast. Instead it was argued that the imaging data suggests shallow processing of DEs.

\section{Acknowledgment}

This work was supported by grants from the Danish National Research Foundation to the Center for Functionally Integrative Neuroscience (CFIN), from the Danish Research Council for the Humanities (under the Ministry of Science, Technology and Innovation) [Grant \#273-06-0248], and from Linguistic Graduate School North, University of Aarhus. Finally, thanks to Frank Thomsen for developing the presentation software.

\section{References}

Aoun, J., \& Li, Y.-A. (1989). Scope and constituency. Linguistic Inquiry, 20(2), 141-172.

Ben-Shachar, M., Hendler, T., Kahn, I., Ben-Bashat, D., \& Grodzinsky, Y. (2003). The neural reality of syntactic transformations: Evidence from fMRI. Psychological Science, 14(5), 433-440.

Ben-Shachar, M., Palti, D., \& Grodzinsky, Y. (2004). Neural correlates of syntactic movement: Converging evidence from two fMRI experiments. Neurolmage, 21, 1320-1336.

Bickerton, D. (2007). Language evolution: A brief guide for linguists. Lingua, 117, 510-526.

Bookheimer, S. (2002). Functional MRI of language: New approaches to understanding the cortical organization of semantic processing. Annual Review of Neuroscience, 25, 151-188.

Bor, D., Cumming, N., Scott, C. E. L., \& Owen, M. (2004). Prefrontal cortical involvement in verbal encoding strategies. European Journal of Neuroscience, 19(12), 3365-3370.

Bor, D., \& Owen, M. (2007). A common prefrontal-parietal network for mnemonic and mathematical recoding strategies within working memory. Cerebral Cortex, $17,778-786$.

Bornkessel, I., Zysset, S., Friederici, A. D., von Cramon, D. Y., \& Schlesewsky, M. (2005). Who did what to whom? The neural basis of argument hierarchies during language comprehension. Neurolmage, 26, 221-233.

Bornkessel-Schlesewsky, I., Schlesewsky, M., \& von Cramon, D. Y. (2009). Word order and Broca's region: Evidence for a supra-syntactic perspective. Brain and Language, 111, 125-139.

Cardillo, E., Aydelott, J., Matthews, P., \& Devlin, J. (2004). Left inferior prefrontal cortex activity reflects inhibitory rather than facililatory priming. Journal of Cognitive Neuroscience, 16(9), 1552-1561.

Christensen, K. R. (2008). Interfaces, syntactic movement, and neural activation: A new perspective on the implementation of language in the brain. Journal of Neurolinguistics, 21(2), 73-103.

Christensen, K. R. (2009). Negative and affirmative sentences increase activation in different areas in the brain. Journal of Neurolinguistics, 22, 1-17.

Corballis, M. C. (1989). Laterality and human evolution. Psychological Review, 96(3), 492-505.

Dapretto, M., \& Bookheimer, S. (1999). Form and content: Dissociating syntax and semantics in sentence comprehension. Neuron, 24, 427-432.

Dogil, G., Ackermann, H., Grodd, W., Haider, H., Kamp, H., Mayer, J., et al. (2002). The speaking brain: A tutorial introduction to fMRI experiments in the production of speech, prosody and syntax. Journal of Neurolinguistics, 15, 59-90.

Ferreira, F., Christianson, K., \& Hollingworth, A. (2001). Misinterpretations of garden-path sentences: Implications for models of sentence processing and reanalysis. Journal of Psycholinguistic Research, 30(1), 3-20.

Ferreira, F., \& Patson, N. D. (2007). The 'Good Enough' approach to language comprehension. Language and Linguistics Compass, 1, 71-83.

Fiebach, C., Schlesewsky, M., Lohmann, G., von Cramon, D. Y., \& Friederici, A. D. (2005). Revisiting the role of Broca's area in sentence processing: Syntactic integration vs. syntactic working memory. Human Brain Mapping, 24, 79-91.

Fiebach, C. J., Vos, S. H., \& Friederici, A. (2004). Neural correlates of ambiguity in sentence comprehension for low and high span readers. Journal of Cognitive Neuroscience, 16(9), 1562-1575.

Fodor, J. D., \& Inoue, A. (1998). Attach anyway. In J. D. Fodor \& F. Ferreira (Eds.), Reanalysis in sentence processing (pp. 101-141). Dordrecht: Kluwer.

Friederici, A. D. (2002). Towards a neural basis of auditory sentence processing. Trends in Cognitive Sciences, 6(2), 78-84. 
Friederici, A. D., Fiebach, C. J., Schlesewsky, M., Bornkessel, I. D., \& von Cramon, D. Y. (2006). Processing linguistic complexity and grammaticality in the left frontal cortex. Cerebral Cortex, 16, 1709-1717.

Frisch, S., Schlesewsky, M., Saddy, D., \& Alpermann, A. (2002). The P600 as an indicator of syntactic ambiguity. Cognition, 85, B83-B92.

Fuster, J. M. (2003). Cortex and mind. Unifying cognition. Oxford: Oxford University Press.

Geurts, B., \& van der Slik, F. (2005). Monotonicity and processing load. Journal of Semantics, 22, 97-117.

Grewe, T., Bornkessel, I., Zysset, S., Wiese, R., von Cramon, D. Y., \& Schlesewsky, M. (2005). Emergence of the unmarked: A new perspective on the languagespecific function of Broca's area. Human Brain Mapping, 26, 178-190.

Grézes, J., \& Decety, J. (2001). Functional anatomy of execution, mental simulation, observation, and verb generation of actions: A meta-analysis. Human Brain Mapping, 12, 1-19.

Hagoort, P. (2005). On Broca, brain, and binding: A new framework. Trends in Cognitive Sciences, 9(9), 416-423.

Hagoort, P., Hald, L., Bastiaansen, M., \& Petersson, K. M. (2004). Integration of word meaning and world knowledge in language comprehension. Science, 304, 438-441.

Hanakawa, T., Honda, M., Sawamoto, N., Okada, T., Yonekura, Y., Fukuyama, H., et al. (2002). The role of Rostral Brodmann area 6 in mental-operation tasks: An integrative neuroimaging approach. Cerebral Cortex, 12, 1157-1170.

Hinzen, W. (2006). Mind design and minimal syntax. Oxford: Oxford University Press.

Inui, T., Otsu, Y., Tanaka, S., Okada, T., Nishizawa, S., \& Konishi, J. (1998). A functional MRI analysis of comprehension processes of Japanese sentences. NeuroReport, 9, 3325-3328.

Johnson, K. (2001). What VP ellipsis can do, what it can't, but not why. In M. Baltin \& C. Collins (Eds.), The handbook of contemporary syntactic theory (pp. 439-479). Blackwell Publishers.

Johnson, K. (2005). Gapping. In M. Everaert \& H. van Riemsdijk (Eds.), The Blackwell companion to syntax (pp. 407-435). Oxford: Blackwell.

Just, M. A., Carpenter, P. A., Keller, T. A., Eddy, W. F., \& Thulborn, K. R. (1996). Brain activation modulated by sentence comprehension. Science, 274, 114-116.

Kiehl, K. A., Liddle, P. F., \& Hopfinger, J. B. (2002). Error processing and the rostral anterior cingulate. Psychophysiology, 37, 216-223.

Kuperberg, G. R., Holcomb, P. J., Sitnikova, T., Greve, D., Dale, A. M., \& Caplan, D. (2003). Distinct patterns of neural modulation during the processing of conceptual and syntactic anomalies. Journal of Cognitive Neuroscience, 15(2), 272-293.

Kurtzman, H. S., \& MacDonald, M. M. (1993). Resolution of quantifier scope ambiguities. Cognition, 48, 243-279.

Lindenberg, R., Fangerau, H., \& Seitz, R. J. (2007). "Broca's area” as a collective term? Brain and Language, 102, 22-29.

Maldjian, J. A., Laurienti, P. J., Kraft, R. A., \& Burdette, J. H. (2003). An automated method for neuroanatomic and cytoarchitectonic atlas-based interogation of fMRI data sets. NeuroImage, 19(3), 1233-1239.

Maldjian, J. A., Laurienti, P. J., Kraft, R. A., \& Burdette, J. H. (2004). Precentral gyrus discrepancy in electronic version of the talairach atlas. Neurolmage, 21(1), 450-455.

Mason, R. A., Just, M. A., Keller, T. A., \& Carpenter, P. A. (2003). Ambiguity in the brain: What brain imaging reveals about the processing of syntactically ambiguous sentences. Journal of Experimental Psychology: Learning, Memory and Cognition, 29(6), 1319-1338.

Merchant, J. (2001). The syntax of silence. Sluicing, islands, and the theory of ellipsis. Oxford: Oxford University Press.

Montalbetti, M.M. (1984). On the interpretation of pronouns. Unpublished Ph.D. diss., Cambridge, MA: MIT.
Myers, J. (2009). Syntactic judgment experiments. Language and Linguistics Compass, 3(1), 406-423.

Natsopoulos, D. (1985). A verbal illusion in two languages. Journal of Psycholinguistic Research, 14(4), 385-397.

Newman, S. D., Just, M. A., Keller, T. A., Roth, J., \& Carpenter, P. A. (2003). Differentia effects of syntactic and semantic processing on the subregions of Broca's area. Cognitive Brain Research, 16, 297-307.

Novick, J. M., Trueswell, J. C., \& Thompson-Schill, S. L. (2005). Cognitive control and parsing: Reexamining the role of Broca's area in sentence comprehension. Cognitive, Affective \& Behavioral Neuroscience, 5(3), 263-281.

Osterhout, L., Holcomb, P. J., \& Swinney, D. A. (1994). Brain potentials elicited by garden-path sentences: Evidence of the application of verb information during parsing. Journal of Experimental Psychology, 20(4), 786-803.

Park, M.-K. (2001). The interaction between movement and ellipsis in the comparative construction in english. Studies in Generative Grammar, 11(2), 447-483.

Pritchett, B. L. (1992). Grammatical competence and parsing performance. Chicago: The University of Chicago Press.

Röder, B. Stock, O, Neville, H. Bien, S. \& Rösler, F. (2002). Brain activation modulated by the comprehension of normal and pseudo-word sentences of different processing demands: A functional magnetic resonance imaging study. Neurolmage, 15, 1003-1014.

Saddy, D., \& Uriagereka, J. (2004). Measuring language. International Journal of Bifurcation and Chaos, 14(2), 383-404.

Sanford, A. J., \& Graesser, A. C. (2006). Shallow processing and underspecification. Discourse Processes, 42(2), 99-108.

Sanford, A. J., \& Sturt, P. (2002). Depth of processing in language comprehension: Not noticing the evidence. Trends in Cognitive Sciences, 6(9), 382-386.

Schubotz, R. I., \& von Cramon, D. Y. (2002). A blueprint for target motion - fMR reveals perceived sequential complexity to modulate premotor. NeuroImage, 16 920-935.

Schubotz, R. I., \& von Cramon, D. Y. (2003). Functional-anatomical concepts of human premotor cortex: Evidence from fMRI and PET studies. NeuroImage, 20 s120-s131.

Shapiro, L. P., Hestvik, A., Lesan, L., \& Garcia, A. R. (2003). Charting the time-course of VP-ellipsis sentence comprehension: Evidence for an initial and independent structural analysis. Journal of Memory and Language, 49(1), 1-19.

Smith, N. (2005). Language, frogs $\mathcal{E}$ savants. More linguistic problems, puzzles and polemics. Oxford: Blackwell.

Smith, E. E., \& Jonides, J. (1999). Storage and executive processes in the frontal lobes. Science, 283, 1657-1661.

Stowe, L. A., Broere, C. A. J., Paans, A. M. J., Wijers, A. A., Mulder, G., Vaalburg, W. et al. (1998). Localizing components of a complex task: Sentence processing and working memory. NeuroReport, 9(13), 2995-2999.

Stowe, L. A., Haverkort, M., \& Zwarts, F. (2005). Rethinking the neurological basis of language. Lingua, 115, 997-1042.

Stowe, L. A., Paans, A. M. J., Wijers, A. A., \& Zwarts, F. (2004). Activations of "motor" and other non-language structures during sentence comprehension. Brain and Language, 89, 290-299.

Stromswold, K., Caplan, D., Alpert, N., \& Rauch, S. (1996). Localization of syntactic comprehension by positron emission tomography. Brain and Language, 52, 452-473.

Uchiyama, Y., Toyoda, H., Honda, M., Yoshida, H., Kochiyama, T., Ebe, K., et al. (2008) Functional segregation of the inferior frontal gyrus for syntactic processes: A functional magnetic-resonance imaging study. Neuroscience Research, 61, 309-318.

Wason, P. C., \& Reich, S. S. (1979). A verbal illusion. The Quarterly Journal of Experimental Psychology, 31(4), 591-597. 